\title{
INSTRUMENTS OF ASSESSMENT FOR FIRST TWO YEARS OF LIFE OF INFANT
}

\author{
Rafaela Silva Moreira', Elyonara Mello de Figueiredo²
}

\begin{abstract}
Introduction: the developmental assessment of infants seeks to identify and classify early developmental delay and /or schedule an intervention. This assessment is considered inefficient when performed only by professional clinical judgment. Thus there are numerous assessment scales to help professionals in this process, requiring a greater knowledge of their advantages and disadvantages. Objectives: to identify and analyze instruments used for assessment of infant development from zero to two years old. Methods: a search was made in the most important databases in the area, in the manual of the instruments used for evaluation and books of Pediatric Physical Therapy. The following data of each standardized instrument were extracted: general characteristics, psychometrics, theoretical basis of each instrument, validity of the instruments for Brazilian children and accessibility of the instruments to the physiotherapist in Brazil. Results: articles about TIMP, DUBOWITZ, MAI, AIMS and BAYLEY-III were selected. The TIMP presents the best indices of reliability and sensitivity for the evaluation of pre-term infants in the four first months of life, however it takes long time to apply and depends on the emotional state of the infant. DUBOWITZ is an instrument that is easy and quick to use although it is not easily found in Brazil. The literature suggests a reevaluation of the MAI instrument as it presents limited psychometric properties, especially a poor validity of construct. AIMS proved to have the best psychometric properties and conditions for clinical use. Bayley III is one the best instruments with high psychometric properties, however it is not of common use in Brazil probably because of the high cost of its application kit. Conclusion: for pre-term infants up to 4 months the TIMP seems to be the instrument of choice, but for longer follow-up up to 18 months, AIMS is the best option, and above this age the Bayley-III scale is adequate as it presents very good psychometric properties.
\end{abstract}

Key words: child development; infant; assessment; reproducibility of tests ; physioterapy.

\section{INTRODUCTION}

Early childhood (zero to two years) is a period of sensory and motor changes marked ${ }^{1}$ by intense interaction with the infants environment ${ }^{2}$, and this is therefore a critical period for child development. Thus from, appropriate assessment of a child's development it is essential of delays and deficiencies ${ }^{3}$ should be detected. This assessment must be peelpsured by the use of valid and reliable scales and not only by clinical judgment, since less than $30 \%$ of developmental disorders are detected by clinical consultation ${ }^{4}$. It should also be observed that in practice phycal therapy for the assessment of infants is not yet to highley systematized. The importance of using tests standardized infants is unquestionable as this may facilitate therapeutic intervention ${ }^{5,6}$ to minimize future sequelae ${ }^{1,3,6-7}$.

The choice of a test must be based on its psychometric properties, the theory of reference, the validity and accessibility of instruments, which includes the cost of the instrument, the need for training and duration of application, time. Professionals report difficulty in using of the these scales due to the few of instruments of assessment that are have been standardized for Brazilian children, which hinders access to and understanding of the psychometric properties of the tests. So don't make use of diagnostic measures standardized and proven efficacy to analyze motor function and determine if there is deviations development. Add also that the scales are standardized to international

1 Fisioterapeuta, Mestranda da Universidade Federal de Minas Gerais - Faculdade de Medicina. Programa de Ciências da Saúde, Área de Concentração: Saúde da Criança e do Adolescente.Belo Horizonte - MG. Titulação: Especialista em Fisioterapia em Neurologia.

2 Fisioterapeuta, Docente do Departamento de Fisioterapia da Universidade Federal de Minas Gerais, Belo Horizonte, Minas Gerais, Brasil. Titulação: Doutora.

Estudo desenvolvido no Departamento de Fisioterapia da Universidade Federal de Minas Gerais, Belo Horizonte, Minas Gerais, Brasil, como requisito para obtenção de grau de Especialista em Fisioterapia em Neurologia.

Trabalho apresentado na forma de pôster no III Congresso Internacional de Especialidades Pediátricas realizado em Curitiba em 2010.

Corresponding author: rafaelafisioterapia@yahoo.com.br

Suggested citation: Moreira RS, Figueiredo EM. Instruments of assessment for first two years of life of infant; Journal of Human Growth and Development 2013; 23(2): 215-221

Manuscript submitted Sep 12 2012, accepted for publication Mai 112012. 
populations with distinct cultures of Brazil, and there not data to confirm whether the psychometric properties these fit Brazilian children ${ }^{3.5}$.

The psychometric properties of instruments assessment refer to their validity and confiabilidade $^{8}$. The validity refers to the ability of a test really measure what it proposes. Different aspects of validity, such as the validity of content that relates to the suitability a test, and criterion validity which subdivides into three types: concurrent validity, predictive and predictable. Concurrent validity compares tested with other test recognized by literature (Gold standard) to demonstrate its ability to measure the same behavior. The validity predictable considers future events being considered often presented in the form of indexes, such as sensitivity and specificity ${ }^{8,9.10}$. Sensitivity refers to the ability of a test to detect a condition when it exists; already specificity refers to the ability test identify the child that shows no deviation or developmental delay. Finally, the construct validity is a concept that integrates considerations of content validity and criterion for testing hypotheses on theories considered importantes ${ }^{8,9}$.

Reliability shows how a test is able, stable and consistent when repeated under identical circumstances. It is subdivided into several types such as: test-retest reliability intra and inter-rater and internal consistency 8,9 . The test-retest is performed by the same examiner and determines whether a score is same or similar when the test is applied under identical conditions. The intra-rater measures the consistency of the same performance made at different times, measured by the same examiner. The interrater reliability measures the consistency of the same performance measured by different examinadores ${ }^{8}$. Internal consistency assesses which elements of assessment instrument those contribute to measure a basic phenomenon. For this there are the intraclass correlation coefficient (ICC) and the coefficient of Pearson ${ }^{1}$.

Besides these properties, the choice of an assessment instrument in child development must still be based on theoretical assumptions underlying the construction of these instruments, since this will influence the conclusions ${ }^{4}$. The neuromaturacional theory is the most traditional and states that acquisitions result of maturation of motor central nervous system and reflect a hierarchical order. In the environment in which the child develops offer little impact on emergency motors skills ${ }^{1,4}$. Contemporary theories call attention to the influence of other physiological and environmental factors as well relevant to child development. The theory of dynamical systems, for example, suggests that besides the nervous system maturation, other physiological systems interact with environmental factors such as weight gain and the gravity action ${ }^{1,4}$.

The objective is to identify and analyze instruments assessment of child development for infants from zero to two years old, as the psychometric properties, the referential theoretical, validity and accessibility of instruments for professionals from Brazil.

\section{METHODS}

Assessment instruments to be reviewed were included because they are standardized assess motor development of infants aged zero two years and to be instruments used in research and clinical practice in Brazil. Were excluded from assessment instruments not used in Brazil, which did not cover the age range (zero to two years) and scientific articles that intervention not detailing the tests.

We searched for articles on the following computerized databases: PubMed, Lilacs, Scielo, Google scholar and PEDro. The strategy of $\mathrm{MeSH}$ search terms included: "Child Development" and "Newborn Screening", "Child Development" and "Assessment instruments" and "Motor Developmental Delay ", names of instruments known to those authors of this review and its respective authors. There was no date restriction to include articles, however there constraint language, and articles that were analyzed in Portuguese, English and Spanish. Were selected 78 articles, these 49 were excluded and were included 29 articles. This total, 12 articles referred to the AIMS instrument, eight to TIMP, seven to scale Dubowitz, seven to scale Bayley and six to MAI. Were also used manuals instruments and books in the field of Pediatric Physical Therapy. Were extracted from each of the selected instruments: general characterization of instrument (simplicity, cost, suitability, advantages and disadvantages); psychometric properties (validity, reliability, sensitivity, specificity); theoretical assumption; validity for Brazilian infants and accessibility of instruments for the physiotherapist in Brazil.

\section{RESULTS}

Were selected the instruments: TIMP, Dubowitz, MAI, AIMS and the Bayley III.

\section{Test of Infant Motor Performance (TIMP)}

The Test of Infant Motor Performance (TIMP) was created by Campbell et al. 1993 aiming to identify motor delay or deficits functional in preterm infants ${ }^{3,5}$. It can be applied in preterm infants from 32 weeks and the term until the age of four months ${ }^{10}$. Presents 42 items and 13 relate to observation of spontaneous activity the baby and 29 others refer to specific behaviors to be noted, using handling techniques ${ }^{4}$ (Table 1 ).

Presents good psychometric properties ${ }^{11}$. Content validity was determined through a review of literature related to expert opinion, pilot studies and reviews content. To construct validity was 
performed the Rash analysis which identified test discriminates infants with low and high risk for motors deficits. The concurrent validity was tested with AIMS, identifying at three months correlation coefficient $r=0.641$ (Table 2). The inter-observer reliability is 0.9512 , the intra-observer varies from 0.98 to 0.991 and the test-retest is 0.89 . It has high sensitivity $(0.92)$ but low specificity $(0.76)^{4}$ (Table 2).

The first version at TIMP was developed with neuromaturacional aspects, however the current version adds an ecological character as which is based on natural movements triggered by babies in their day-to-day ${ }^{3}$. Not there validation testing for Brazil. The duration for applying is 20 to 40 minutes and the test provides equipment needed for its administration. There is need for training from a DVD instructional and reading the manual (Table 1). The manual and the test cost $\$ 601$.

\section{Neurological Examination of the Dubowitz Full- term Newborn (Dubowitz)}

This neurological assessment of preterm infants and the full term was created in 1981 by Dubowitz and Dubowitz, aiming to detect neurological deficits and neurobehavioural. The age group ranges from preterm infants under one year old ${ }^{13}$. The instrument is composed of 15 items that assess muscle tone, six items of primitive reflexes, nine items neurobehavioral and six status categories behavior (Table 1 ). It is not necessary to apply all items examining whether the conditions infant not permit ${ }^{14}$. After administration infants are classified as normal, borderline or abnormal ${ }^{5}$. The application time test ranges from 10 to 15 minutes.

The intra-examiner reliability is above $96 \%$, has good sensitivity ( $88 \%)$; but poor specificity (34\%) ${ }^{14,15}$ (Table 2 ). The content validity was established through pilot study and literature reviews with experts in the area ${ }^{14}$ (Table 2 ). Presents as reference neuromaturacional theory because its content relates if the maturation of the central nervous system, having assessment items focused, for example, in primitive reflexes. It is an instrument that requires no formal training due to simplicity fill the test ${ }^{14,15}$. The instrument is not validated for Brazil and there is limited access because little information by internet (Table 1 ).

\section{Movement Assessment of Infants (MAI)}

The test was created in 1980 by physiotherapists North America to assess the neuromotor function in infants under one year of age, mainly high-risk infants. Assesses four areas of development (tone, reflexes primitive, automatic reactions and rectification voluntary movements) through 65 items. Each item is scored in a specific way and if the score of an item differs from what is considered normal the infant receives a risk point $3,5,16$. As the greater the risk score is worse infant prognosis ${ }^{17}$. It has no normative scores, however were created performance profiles for 4 and 8 months, with a score more than 13 at four months total is indicative of deficit neuromotor, mostly cerebral palsy, to eight months a score greater than ten is cerebral ${ }^{3}$ indicative of cerebral palsy.

The reliability and validity of the MAI are low: inter-observer reliability from 0.72 to 0.91 , testretest 0.76 to 0.79 , and low specificity ( $72 \%$ at four months and $59 \%$ at eight months), however has high sensitivity ( $83 \%$ at four months and $96 \%$ at eight months) ${ }^{18,19}$ (Table 2). Its content validity was determined from literature review and the risk scores of high-risk infants (Table 1 ). The validity construct presents that the instrument discriminates infants with normal and abnormal development in preterm infants, but not the done to even healthy full-term infants. The concurrent validity was carried out using the Bayley, with $r=0.63$ at four months for full-term babies and preterm. It has good predictive validity for the diagnosis cerebral palsy (CP) in North american ${ }^{1}$, with $81 \%$ identity of CP to four months, however it was detected a high number false positive $(44 \%)^{6}$, presenting low sensitivity (Table 2).

The MAI was built from the perspective of neuromaturacional theory, with little emphasis the observation of spontaneous movement of infant and environmental context ${ }^{5}$. Although not there validation test for Brazil, the MAI is being used in country $3,5,16$. The test presents a manual and requires no specific equipment, however, requires some skill of the examiner (Table 1 ). The application environment should be pleasant, with ample space and its duration can vary 6090 minutes whereas the time for completing test $3,5,14$ (Table 1 ).

\section{Alberta Infant Motor Scale (AIMS)}

Instrument of assessment published in 1994 by physiotherapists Canadians who identifies infants aged zero to 18 months with developmental delay motor. It is easy to apply and quick administration (20 to 30 minutes) ${ }^{4,5,14}$ (Table 1 ). The environment for assessment MUST be peaceful and pleasant. The assessment is made of infants at different postures and appraiser establishes the most primitive and the most evolved for this infant, thus defining a window of motor skills. Each item receives one score when the ability was observed and zero score if there was not seen by the examiner. This score is summed and added the age of the infant being transferred to a graph of percentile performance of lactente $^{4}$. The higher the percentiles lower the chance of delayed development motor ${ }^{10,19}$.

The instrument presents items related to two theories studied ${ }^{3,15}$. The neuromaturacional theory determined the sequence of the items motors while the theory of dynamical systems based the importance of observing the infant's movement spontaneous during free interaction with its ambiente $^{4}$ (Table 1 ). The AIMS was validated recently for the Brasil ${ }^{20}$ and also to monitor the development brazilian preterm infant ${ }^{21}$. According to his authors there is no need for training its 
application, however, it is necessary for the professional have knowledge about children development (Table 1 ). There is a manual guidance which costs $\$ 80$, available for purchase at Internet ${ }^{1,3}$.

\section{Bayley Scales of Infant Development III (BSID III)}

In 1953 was created the first version that was reviewed in 1993 and 2005 and named Bayley Scales of Infant Development III ${ }^{5}$. Aims to detect developmental delays and comprises across five domains (cognitive scale, motor, language, social and emotional behavior adaptive) ${ }^{22,23}$. It is an instrument the U.S. developed for the age group between one and 42 months with duration of application ranging from 30 to 90 minutes depending on the age of the child and ability of the evaluator (Table 1). It can be applied even in preterm infants, HIV children, or with autistic syndrome or Down ${ }^{22-24}$. The scale consists of 72 items gross motor and fine motor for 66 itens ${ }^{22}$, the language domain consists of 97 items and the cognitive scale by 91 items. The environment for the examination should be quiet, well ventilated and illuminated, with enough space for the child walk, run and jump. The score is to provide one point for a child's behavior observed and zero for not observed behavior ${ }^{10,22}$.

Has good reliability and validity ${ }^{22,25}$. Content validity was conducted through literature review, expert opinion and pilot studies. The validity of construct established that the constructs become more differentiated with age. The validity concurrent was performed with a motor development scale
Peabody II, yielding $r=0.85$ to 0.97 (Table 2 ). The interrater reliability is $r=0.75$ (motor) and $r=0.96$ (mental). The test-retest reliability was $r=0.78$, $r=0.87$ (mental) and $r=0.55$ to 0.90 (behavioral) (Table 2) ${ }^{24}$.

The BSID III is considered an assessment that addresses both concepts theory neuromaturacional, such as the development sequence cephalocaudal and near distal as the dynamic theory as it indicates the importance functionality and the interaction of subsistemas ${ }^{22}$. The instrument has not been validated for Brazil, however the use of this scale is possible $^{5}$, while still be little used. The BSID is expensive, U.S. $\$ 1,075$, it requires use of specific kit with stimulus materials that includes a manual. There is a need for a training profissionais ${ }^{10,22}$ for application (Table 1).

\section{DISCUSSION}

This review identified five instruments to assess development of infants zero to two years old, preterm or full-term that have different psychometric properties, theoretical and clinical applicability, besides financial costs varied. The choice of an instrument should be based the appropriateness of the objectives of the researcher/ practitioner, in the population being assessed, the properties psychometric testing and accessibility the physiotherapist.

Newborn preterm exhibit different development patterns when compared with fullterm infants, justifying the use of assessments built specifically for this population. The instruments

Table 1: Key characteristics instruments of assessment in the first two years of life

\begin{tabular}{|c|c|c|c|c|c|c|}
\hline Instrument & $\begin{array}{l}\text { Aspects } \\
\text { evaluated }\end{array}$ & $\begin{array}{c}\text { Age range } \\
32 \text { weeks of IG }\end{array}$ & $\begin{array}{c}\text { Time to } \\
\text { administer }\end{array}$ & $\begin{array}{c}\text { Validity in } \\
\text { Brasil }\end{array}$ & Training & $\begin{array}{l}\text { Theoretical Basis } \\
\text { Gross motor }\end{array}$ \\
\hline TIMP & Gross motor & a 4 month & 20 a $40^{\prime}$ & no & yes & $\begin{array}{l}\text { Neuromaturacional theory } \\
\text { and sand dynamic systems }\end{array}$ \\
\hline DUBOWITZ & 0 a 12 months & 10 a $15^{\prime}$ & no & no & & Neuromaturacional theory \\
\hline MAI & Fine and gross motor & 0 a 1 year old & 60 a $90^{\prime}$ & no & no & Neuromaturacional theory \\
\hline AIMS & Gross motor & 0 a 18 months & 20 a $30^{\prime}$ & yes & no & $\begin{array}{l}\text { Neuromaturacional theory } \\
\text { and dynamic systems }\end{array}$ \\
\hline BAYLEY III & $\begin{array}{l}\text { Fine and gross motor, } \\
\text { language, cognition, } \\
\text { behavior and } \\
\text { emotional social }\end{array}$ & 1 a 42 months & 30 a $90^{\prime}$ & no & yes & $\begin{array}{l}\text { Neuromaturacional theory } \\
\text { and dynamic systems }\end{array}$ \\
\hline
\end{tabular}

AIMS, Alberta infant motor scale; BAYLEY III, Bayley scales of infant-version II; DUBOWITZ, Neurological assessement of the preterm and full-term newborn infant; MAI, Motor assessment infant; TIMP, Test of infant motor performance;--: item not found in literature. 
Table 2: Validity and reliability of instruments of assessment in the first two years of life

\begin{tabular}{|c|c|c|c|c|c|c|c|c|}
\hline Instrument & Content & $\begin{array}{l}\text { Construct } \\
\text { Validity }\end{array}$ & $\begin{array}{l}\text { Concurrent } \\
\text { Validity }\end{array}$ & $\begin{array}{l}\text { Sensitivity } \\
\text { Validity }\end{array}$ & Specificity & Test-retest & Intrarater & Interrater \\
\hline TIMP & $\begin{array}{l}\text { Literature review, pilot } \\
\text { study with experts, } \\
\text { review of content }\end{array}$ & $\begin{array}{l}\text { Discriminates infants with low } \\
\text { and high risk of motor } \\
\text { problems }\end{array}$ & $\begin{array}{c}\text { AIMS (3 meses) } \\
r=0,64\end{array}$ & $r=0,92$ & $r=0,76$ & $r=0,89$ & $\begin{array}{c}\text { ICC }=0,98 \\
\text { a } 0,99\end{array}$ & $\mathrm{ICC}=0,95$ \\
\hline DUBOWITZ & $\begin{array}{l}\text { Literature review, } \\
\text { pilot study with experts }\end{array}$ & -- & -- & $88 \%$ & $34 \%$ & $r>36 \%$ & -- & -- \\
\hline MAI & $\begin{array}{l}\text { Literature review; } \\
\text { risk scores based on } \\
\text { high risk infants }\end{array}$ & $\begin{array}{l}\text { Discriminate normal from } \\
\text { abnormal development in } \\
\text { preterm infants, but not } \\
\text { the same in healthy } \\
\text { full-term infants }\end{array}$ & $\begin{array}{c}\text { Bayley } \\
\text { (4 months) } \\
r=0,63 \\
\text { for full-term } \\
\text { and preterm } \\
\text { babies }\end{array}$ & $\begin{array}{l}83 \% \text { to } \\
4 \text { months } \\
\text { and } 96 \% \\
\text { to } 8 \\
\text { months }\end{array}$ & $\begin{array}{l}72 \% \text { to } \\
4 \text { months; } \\
59 \% \text { to } \\
8 \text { months }\end{array}$ & $\begin{array}{c}r=0,76 \\
\text { a } 0,79\end{array}$ & -- & $\begin{array}{c}r=0,72 \\
\text { a } 0,91\end{array}$ \\
\hline AIMS & $\begin{array}{l}\text { Literature review, } \\
\text { pilot study with experts }\end{array}$ & $\begin{array}{l}\text { Discriminate normal } \\
\text { development of } \\
\text { abnormal and suspicius }\end{array}$ & $\begin{array}{l}\text { Bayley } \\
r=0,98 \\
\text { Peabody } \\
r=097\end{array}$ & $\begin{array}{l}77,3 \text { to } \\
86,4 \% \text { at } \\
4 \text { months }\end{array}$ & $\begin{array}{l}65,5 \text { at } \\
8 \text { months }\end{array}$ & $\mathrm{ICC}=0,99$ & $\begin{array}{c}0 \text { a } 18 \mathrm{~m} \\
(\mathrm{ICC}=0,99)\end{array}$ & $\begin{array}{l}0 \text { to } 18 \mathrm{~m} \\
(\text { ICC }=0,997)\end{array}$ \\
\hline BAYLEY III & $\begin{array}{l}\text { Literature review, } \\
\text { pilot study with experts }\end{array}$ & $\begin{array}{l}\text { Constructs are differentiated } \\
\text { with age, there is a } \\
\text { correlation of items } \\
\text { within each scale }\end{array}$ & $\begin{array}{c}\text { Peabody }-2: \\
r=0,85-0,97\end{array}$ & -- & -- & $\begin{array}{l}r=0,78 \\
\text { (motor) } \\
r=0,87 \\
\text { (mental) }\end{array}$ & -- & $\begin{array}{l}r=0,75 \\
\text { (motor) } \\
r=0,96 \\
\text { (mental) }\end{array}$ \\
\hline
\end{tabular}

AIMS, Alberta infant motor scale; BAYLEY III, Bayley scales of infant-version III; DUBOWITZ, Neurological assessment of the preterm and full-term newborn infant; MAI, Motor Motor assessment infant; TIMP, Test of infant motor performance;--: item not found in literature; r, Pearson coefficient, ICC; intraclass correlation coefficient.

Dubowitz, TIMP and the MAI, are specific to infants who were born prematurely and must, therefore, be used in follow-up programs. Also, knowing stability and the predictive ability of an instrument can be determinant for infants born prematurely as its results can be used to indicate the need intervention and inform parents prognosis your child. However it should be done cautiously because existing instruments do not appear to be capable of detecting all variations development in the first year of life. The plasticity of a child can lead changes in brain function and thereby explain the difficulty of predicting an outcome with overall accuracy. These predictions are more effective in the case of infants with severe disabilities such as cerebral palsy. In milder cases the influence of environmental factors, social and biological and the interaction of these impediments to that prediction.

The TIMP, among the instruments analyzed, presents better reliability and sensitivity in the first three months of life, is designed for evaluation of abnormalities precoces ${ }^{1,11}$. Thus it has been used in studies randomized controlled of intervention achieving detect significant differences between groups. However, its application is delayed and depends on the emotional state of lactente ${ }^{1}$. Already
Dubowitz test is a quick and easy application although not very accessible to the physiotherapist Brazilian. Presents well intraexaminer correlation and reliability, and is an effective method and sensitive to reveal changes neuromotor of preterm infants and full-term ${ }^{14,15}$. In their study Molteno et al (1995) stated that the presence of four or more deviations in the Dubowitz indicate a poor prognosis for the infant and a greater likelihood of development deficits ${ }^{13}$. A disadvantage test is to simply focus on neurological aspects, without performing a global assessment of infant and not have to worry that the interaction infants in their environment and context.

The MAI is a test developed to identify and monitor early intervention, however several studies have questioned its appropriateness these objetivos $^{17,18}$. The instrument is shown to be sensitive to the identification of abnormalities four months of age, with moderate scores specificity. Cardoso et al (2004) has found that the MAI presents clinical usefulness for the detection of cerebral palsy in infants preterm Brazilians, although this test was more specifically to discriminate infants with development normal compared those patients with Cerebral Palsy. The test exhibits a limited 
psychometric base and a poor validity construct ${ }^{18,}$ 19. The literature suggests that items MAI are reassessed, suitable for the age group, making the instrument shorter and less stressful for infants.

Already the AIMS assessments among surveyed presents the best psychometric properties clínico ${ }^{11}$ and conditions for use. It is the best predictor atypical motor development, has the highest reliability. It has the advantage of being easily applicable, since it is a fast, allied a manual for easy understanding. It is one of tests commonly used in the country being validated for Brazil by Sacanni and $\mathrm{col}^{20}$. Almeida et al (2008) demonstrated that this test is also valid and reliable for use in brazilian infants at risk ${ }^{21}$.

The Bayley-III scale is among the best instruments of assessment child development ${ }^{26}$. The results obtained by the sub-scales mental and motor are useful to provide family feedback about your child's development, serving to monitor the progress of treatment of children with motor disorders. It still useful for making decisions on intervention early $^{26}$. Data from this scale are considered valid, reliable and objective, and extensively used in

\section{REFERENCES}

1 Spittle AJ, Doyle LW, Boyd RN . A systematic review of the clinimetric properties of neuromotor assessments for preterm infants during the first year of life. Developmental Medicine \& Child Neurology 2008; 50:254-266.

2 Bly, L. Motor skills acquisition in the first year: an illustrated guide to normal development. Therapy Skill Builders; 1994.

3 Santos RS, Araújo APQC, Porto MAS. Early diagnosis of abnormal development of preterm newborns: assessment instruments. Jornal de Pediatria 2008; 84(4).

4 Piper M, Darrah J. Motor Assessment of The Developing Infant. Philadelphia: W.B. Company; 1994.

5 Vieira MEB, Ribeiro FV, Formiga CKMR. Principais instrumentos de avaliação de desenvolvimento da criança de zero a dois anos de idade. Revista Movimenta 2009; 2(1).

6 Mancini MC, Teixeira S, Araújo LG, Magalhães LC, Coelho, ZAC. Estudo do desenvolvimento da função motora aos 8 e 12 meses de idade em crianças nascidas pré-termo e a termo. Arq. neuropsiquiatr 2002; 60(4): 974-980.

7 Snider L, Majnemer A, Mazer B, Campbell S, Bos AF. Prediction of Motor and Functional Outcomes in Infants Born Preterm Assessed at Term. Pediatric Physical Therapy 2009; 21: 2-11.

8 Portney LG, Watkins MP. Foundations of clinical research: applications to practice. 3 ed. Pearson: prentice hall; 2009.

9 Burton AW. Movement Skill Assessment. University of Minnesota: ed Human Kinetics; 1998. scientific research 22 . Although it is widely used abroad, the Bayley III is yet little used in Brazil for being an instrument tiring fot the children, costly, requiring specific training, usually offered in the USA $^{23}$.

Considering the target population, the properties psychometric tests analyzed, the theoretical benchmark, validity and accessibility of instruments in Brazil, for assesment of infants preterm up to four months of life, TIMP seems be the best choice. As for infants up 18 months, AIMS presents the results reliable, and above this age, the Bayley-III can achieve the proposed goals efficiently. However it is important to note that only AIMS has been validated for the Brazilian population. Assuming that cultural factors and environmental stimuli such as the caregiver may influence child development, results all these tests must be interpreted carefully, taking into consideration environmental aspects of specific each child. Furthermore, studies of validation instruments which have the best psychometric properties are fundamental, of order to be culturally adapted and used without restriction to the Brazilian population.

10 Heineman K R, Hadders-Algra M. Evaluation of Neuromotor Function in Infancy-A Systematic Review of Available Methods. J Dev Behav Pediatr 2008; 29:315-323.

11 Majnemer A, Snider L. A comparison of developmental assessments of the newborn and young infant. Mental retardation and developmental disabilities. Research Reviews 2005; $11: 68-73$.

12 Herrero D, Gonçalves H, Siqueira AAF, Abreu LC. Escalas de desenvolvimento motor em lactentes: Test of infant motor performance e a Alberta infant motor scale. Rev Bras Crescimento Desenvolvimento Hum. 2011; 21(1): 122-132

13 Molteno C, Grosz P, Wallace P, Jones M. Neurological examination of the preterm and fullterm infant at risk for developmental disabilities using the Dubowitz Neurological Assessment. Early Human Development 1995; 41:167-176.

14 Dubowitz L; Dubowitz V. The neurological Assessment of the preterm and full-term newborn infant. Clinics in Developmental medicine $1981 ; 79$.

15 Dubowitz L, Ricci D, Mercuri E. The dubowitz neurological examination of the full-term newborn. Mental retardation and developmental disabilities 2005; 11:52-60.

16 Woodward LJ, Mogridge N, Scott WW, Terrie EI. Can Neurobehavioral Examination Predict the Presence of Cerebral Injury in the Very Low Birth Weight Infant? Developmental and Behavioral Pediatrics 2004; 25(5).

17 Magalhães LV, Lacerda TTB. Análise da validade dos itens do Movement Assesment of infants-MAI- para crianças pré-termo. Revista 
Brasileira de Saúde Materno infantil 2006; 6(3): 297-308.

18 Cardoso AA, Magalhães LC, Amorim RHC, Paixão ML, Mancini MC, Rossi LDF. Validade preditiva do Movement Assesment of Infants para crianças pré-termo brasileiras. Arquivos de Neuropsiquiatria 2004; 62(4).

19 Manacero S, Nunes ML. Evaluation of motor performance of preterm newborns during the first months of life using the Alberta Infant Motor Scale (AIMS). Jornal de Pediatria 2008; 84(1).

20 Valentini NC, Saccani R. Brazilian Validation of the Alberta Infant Motor Scale. Physical Therapy 2012; 92:440-447.

21 Almeida KM, Dutra MVP, Mello RR, Reis ABR, Martins PS. Validade concorrente e confiabilidade da Alberta Infant Motor Scale em lactentes nascidos prematuros. Jornal de Pediatria 2008; 84(5).
22 Bayley, N. Bayley scales of infant and toddler development.3ed. San Antonio: Pearson; 2006.

23 Silva NDSH, Filho FL, Gama MEAG et al. Instrumentos de avaliação do desenvolvimento infantil de recém-nascidos prematuros. Rev. Bras. Cresc. e Desenv. Hum. 2011; 21(1): 85-98.

24 Harris SR, Megens AM, L Backman CL, Hayes VEH. Stability of the Bayley II Scales of Infant Development in a sample of low-risk and highrisk infants. Developmental Medicine \& Child Neurology 2005; 47: 820-823.

25 Weiss L G, Oakland T, Aylward G. Bayley-III Clinical Use and Interpretation - 2010. [Livro online]. [Acesso em 16 abr 2012]. Disponível em: http://books.google.com.br/books.

26 Jackson, BJ, Needelman H, Roberts H, Willet S, Mcmorris C. Bayley Scales of Infant Development Screening Test-Gross Motor Subtest: efficacy in determining need for services. Pediatric physical therapy / 2012; 24(1): 58-62. 